JKM (Jurnal Kebidanan Malahayati),Vol 7,No.3.Juli 2021,

ISSN (Print) 2476-8944 ISSN (Online) 2579-762X, Hal 481-488

\title{
KESEDIAAN IBU DALAM PEMERIKSAAN INSPEKSI VISUAL ASAM ASETAT (IVA)
}

\author{
Sri Juliani', Nurrahmaton ${ }^{2}$, Sahyuni Sari Marbun ${ }^{3}$ \\ 1;2,3Prodi D4 Kebidanan Institut Kesehatan Helvetia \\ *Korespondensi email : srijuliani@helvetia.ac.id
}

\section{ABSTRACT MOM'S WILLING TO CHECK ACETIC ACID VISUAL INSPECTION}

Background: Cervical cancer is cancer with the highest prevalence in women in Indonesia. VIA examination is done to check for early signs and symptoms of cervical cancer. In Sunggal Health centre, out of 10,616 women of childbearing age (WCA) who underwent 451 (4.25\%) suspected VIA examinations.

Objective: This study aimed to determine the factors that affect the availability of WCA to undergo VIA examinations at Sunggal Health centre in 2020.

Method: This study was an analytic survey with a cross-sectional approach. The populations were 47 women. The sample was 32 people by accidental sampling. Data were analyzed by performing Chi-square and binary logistic tests.

Results: The results showed that it was found that a relationship between willingness of WCA to undergo VIA examination and; knowledge with a sig. value of .01; attitudes with a sig. value of .005. and the role of health workers with a sig. value of 0.000 . Meanwhile, the job variable had no relationship with the willingness of WCA to undergo VIA examinations with a sig. value of .166. The most dominant variable in VIA examination is the role of health workers with the EXP (B) value of 19.257.

Conclusion: The conclusion is a relationship between knowledge, attitudes and roles of health workers in VIA examinations at Sunggal Health centre in 2020 found.

Suggestion that health workers be more active in providing counselling about VIA examinations in order to increase motivation to carry out examinations.

Keywords: Knowledge, attitudes, health workers, occupation, VIA examination

\section{ABSTRAK}

Latar Belakang: Kanker serviks merupakan kanker yang tertinggi prevalensinya pada perempuan di Indonesia. Pemeriksaan IVA dilakukan untuk mendeteksi secara dini tanda dan gejala kanker serviks. Di Puskesmas Medan Sunggal dari 10.616 WUS yang melakukan pemeriksaan IVA berjumlah 451 (4,25\%). Menunjukkan rendahnya cakupan pemeriksaan IVA di Puskesmas Sunggal.

Tujuan: Penelitian ini untuk mengetahui determinan kesediaan WUS dalam pemeriksaan IVA untuk mendeteksi dini kanker leher rahim di Puskesmas Sunggal tahun 2020.

Metode: Jenis penelitian adalah survey analitik dengan pendekatan cross sectional. Populasi dalam penelitian adalah WUS yang berkunjung ke Puskesmas sebanyak 47 orang. Sampel dalam penelitian sebanyak 32 orang, tehnik pengambilan sampel dengan cara accidental sampling. Data dianalisis dengan melakukan uji analisis Chi-square dan binary logistik.

Hasil: penelitian menunjukkan ada hubungan pengetahuan dengan kesediaan WUS dalam pemeriksaan IVA dengan nilai signifikan 0,01; ada hubungan sikap dengan kesediaan WUS dalam pemeriksaan IVA dengan nilai signifikan 0,005. Ada hubungan peran petugas kesehatan dengan kesediaan WUS dalam pemeriksaan IVA dengan nilai signifikan 0,000 . Sedangkan variabel pekerjaan tidak ada hubungan dengan kesediaan WUS dalam pemeriksaan IVA dengan nilai signifikan 0,166 . Variabel paling dominan dalam pemeriksaan IVA yaitu peran petugas kesehatan yaitu dengan nilai $\operatorname{EXP(B)~sebesar~19.~} 257$.

Kesimpulan: ada hubungan pengetahuan, sikap dan peran petugas kesehatan dalam pemeriksaan IVA di Puskesmas Sunggal tahun 2020.

Saran: Disarankan kepada petugas kesehatan lebih meningkakan promosi kesehatan dan menjadwalkan penyuluhan tentang pemeriksaan IVA dalam mendeteksi dini kanker leher rahim.

Kata Kunci : Pengetahuan, sikap, peran petugas kesehatan, pekerjaan, Pemeriksaan IVA 


\section{PENDAHULUAN}

Metode Inspeksi Visual dengan Asam Asetat test (IVA) merupakan metode screening yang lebih praktis, murah, dan memungkinkan dilakukan di Indonesia. Dan pencegahan penyakit dengan metode deteksi ini merupakan bentuk dari sebuah praktik kesehatan atau tindakan hidup sehat (Tilong 2012).

Kebijakan interval skrining di pengaruhi oleh kebijakan setiap Negara. Interval skrining menurut rekomendasi WHO sebagai berikut: Jika fasilitas kesehatan terbatas hanya $1 \times$ pada umur $35-40$ tahun. Jika fasilitas cukup tiap 10 tahun pada umur 35-55 tahun.Jika fasilitas lebih tiap 5 tahun pada umur 35-55 tahun.Ideal tiap 3 tahun pada perempuan umur 25-60 tahun (Marmi 2015).

Berdasarkan data Globocan, International Agency for Research on Cancer (IARC) tahun 2018, terdapat 18,1 juta kasus baru dan 9,6 juta kematian. Menurut perkiraan globocan ada 569.847 kasus baru kanker leher rahim di seluruh dunia dan 61.072 kasus baru kanker leher rahim di Eropa. Pada tahun 2018, diperkirakan ada 311.365 kematian akibat kanker leher rahim di seluruh dunia dan 25.829 kematian akibat kanker leher rahim di Eropa (3,0\%) (Release 2018).

Berdasarkan Data Kemenkes RI tahun 2019, angka kejadian penyakit kanker di Indonesia (136,2/100.000 penduduk) berada pada urutan $8 \mathrm{di}$ Asia Tenggara, sedangkan di Asia urutan ke 23. Angka kejadian kanker untuk perempuan yang tertinggi adalah kanker payudara (Kementrian Kesehatan RI 2019). Sedangkan Rekapitulasi deteksi dini kanker leher rahim dengan pemeriksaan IVA di Provinsi Sumatera Utara menurut Kemenkes RI pada tahun 2015 sebanyak 16.232 wanita PUS melakukan deteksi dini kanker leher rahim dengan pemeriksaan IVA (Indonesia 2018).

Menurut Profil Kesehatan provinsi Jawa Tengah tahun 2019, Jumlah WUS yang melakukan pemeriksaan untuk deteksi dini kanker leher rahim dan kanker payudara dilaporkan sebanyak 54.844 WUS dari perempuan usia 30-50 tahun. (Dinkes Provinsi Jawa Tengah 2019).

Menurut Profil Kesehatan Sumatera Utara tahun 2018, cakupan deteksi dini kanker leher rahim dengan pemeriksaan IVA dan kanker payudara dengan pemeriksaan Klinis (CBE) yaitu Tapanuli Selatan menempati urutan yang paling banyak dengan hasil IVA positif yaitu 39 WUS sedangkan Kota Medan menempati urutan pertama dengan hasil IVA positif 74 WUS (Dinas Kesehatan Provinsi Sumatera Utara 2018).
Di Puskesmas Medan Sunggal dari 10.616 WUS yang berusia 30-50 tahun, yang melakukan pemeriksaan leher rahim dan pemeriksaan payudara klinis berjumlah $451(4,25 \%)$ dengan hasil pemeriksaan IVA positif sebanyak 9 orang WUS $(0,09 \%)$ (Kesehatan and Medan 2016).

Data Puskesmas Sunggal bulan November sampai dengan Desember tahun 2019 didapatkan ibu yang melakukan pemeriksaan IVA di Poli KIA (Kesehatan lbu dan Anak) yaitu dari 37 ibu WUS, IVA positif sebanyak 7 orang dan IVA negatif sebanyak 30 orang. Ibu yang hasil pemeriksaan IVA positif dilakukan rujukan ke Rumah Sakit untuk pemeriksaan lebih lanjut. Sedangkan ibu yang hasil pemeriksaan IVA negatif diberikan penyuluhan untuk menjaga kebersihan alat kelamin dan mengikuti pemeriksaan IVA 5 tahun yang akan datang.

Kanker payudara dan kanker leher rahim merupakan jenis kanker yang tertinggi prevalensinya pada perempuan di Indonesia. Kedua kanker ini dapat ditemukan pada tahap yang lebih dini, akan tetapi saat ini kanker lebih sering diketahui pada stadium lanjut (70\%) sehingga angka kematiannya tinggi. Kanker leher rahim dapat ditemukan pada tahap sebelum kanker (lesi prakanker) dengan metode IVA dan papsmear. Jika ditemukan pada tahap lebih dini dapat menurunkan angka kematian dan menghemat pembiayaan kesehatan yang sangat tinggi, terutama dari kedua kanker ini. Sampai dengan tahun 2017 sudah dilakukan deteksi dini kanker leher rahim dan payudara terhadap 3.040 .116 perempuan usia 3050 tahun (2,98\%) di Indonesia (Indonesia 2018).

Kesadaran perempuan Indonesia untuk melakukan deteksi dini kankerserviks secara teratur masih rendah. Cakupan deteksi dini di Indonesia kurang dari 5\% sehingga banyak kasus kanker leher rahim ditemukan pada stadium lanjut yang seringkali menyebabkan kematian. Ada beberapa faktor yang mendukung wanita PUS (Pasangan Usia Subur) melakukan pemeriksaan IVA yaitu : Faktor pengetahuan dan dukungan keluarga. Masalah lain dalam usaha skrining kanker leher rahim ialah keengganan wanita diperiksa karena malu (Fallis 2013).

Salah satu upaya yang dilakukan untuk penanganan kanker leher rahim adalah melakukan program deteksi dini melalui metode inspeksi visual asam asetat (IVA). Program IVA telah berjalan di 3.265 Puskesmas yang tersebar di 379 kabupaten/kota yang berada di 34 provinsi di Indonesia dengan tenaga terlatih yang terdiri dari 


\section{JKM (Jurnal Kebidanan Malahayati),Vol 7,No.3.Juli 2021, ISSN (Print) 2476-8944 ISSN (Online) 2579-762X, Hal 481-488}

2.611 orang dokter dan 5.397 orang bidan (Biro Komunikasi dan Pelayanan Masyarakat 20116).

Penelitian yang dilakukan oleh Devy Lestari Nurul Aulia danYulisa Neno (2019) menjelaskan ada hubungan bermakna antara pengetahuan dan sikap dengan keikutsertaan pekerja seks komersial dalam melakukan pemeriksaan IVA (Aulia and Neno 2019). Penelitian yang dilakukan oleh Nurhimah Apriyanti, dkk (2020) menjelaskan ada hubungan peran petugas kesehatan dengan pemeriksaan ca serviks menggunakan metode visual asam asetat (IVA) (Apriyanti et al. 2020). Penelitian yang dilakukan oleh Nur'aini dan Marinta Ulina (2020) menjelaskan ada pengaruh pekerjaan terhadap tindakan wanita usia subur dalam deteksi dini kanker leher rahim melalui pemeriksaan tes IVA(Soebandi n.d.).

Berdasarkan survey awal yang dilakukan peneliti di Puskesmas Sunggal Kecamatan Medan Sunggal pada tanggal 15 Januari 2020, dari hasil wawancara kepada 10 orang ibu didapatkan bahwa seluruh ibu belum pernah melakukan pemeriksaan IVA dengan alasan responden mengatakan tidak mengetahui tentang tes IVA sebagai alat untuk pemeriksaan kanker leher rahim dan sebelunya belum pernah mendengar pemeriksaan IVA untuk mendeteksi kanker leher rahim. Sebagian mengatakan tidak bersedia melakukan pemeriksaan IVA karena responden merasa tubuhnya sehat dan tidak ada keluhan dibagian alat kelamin, sehingga lebih memilih memeriksakan penyakit yang memang sudah dideritanya seperti rematik, asam urat, hipertensi. Sebagian responden juga mengatakan tidak pernah mendapat penyuluhan dari petugas kesehatan di Puskesmas tentang pemeriksaan IVA sehingga mereka tidak tahu bahwa ada pemeriksaan IVA di Puskesmas. Selain itu, alasan pekerjaan juga menjadi alasan ibu sehingga tidak melakukan pemeriksaan IVA. Kebanyakan dari mereka bekerja sebagai buruh pabrik yang bekerja pada pagi hari dan selesai pada sore hari sehingga tidak memiliki kesempatan untuk melakukan pemeriksaan IVA.

Penelitian ini bertujuan untuk mengetahui faktor apa yang mempengaruhi kesediaan WUS dalam pemeriksaan IVA di Puskesmas Sunggal Tahun 2020.

\section{METODOLOGI PENELITIAN}

Jenis penelitian adalah survey analitik dengan pendekatan cross sectional. Populasi dalam penelitian adalah WUS yang berkunjung di Puskesmas Medan Sunggal, teknik pengambilan sampel menggunakan accidental sampling. Jumlah sampel dalam penelitian ini sebanyak 32 orang.
Jenis Penelitian ini merupakan penelitian kuantitatif dengan menggunakan survei analitik dengan metode pendekatan cross sectional. Sumber data diambil dari data primer, sekunder dan tersier. Data primer menggunakan kuesioner berisi pernyataan-pernyataan tentang variabel penelitian yaitu pengetahuan ibu, sikap ibu, dan peran petugas kesehatan. Data sekunder menggunakan catatan kunjungan pasien di Puskesmas Sunggal. Data tersier menggunakan jurnal dan website resmi.

Analisa data menggunakan program komputer, analisa univariat digunakan untuk mendeskripsikan data yang dilakukan pada tiap variabel dari hasil penelitian. Data disajikan dalam tabel distribus frekuensi. Analisa bivariat diguanakan untuk mengetahui hubungan antara variabel bebas dengan variabel terikat. Analisa bivariat menggunakan uji chi-square. Analisa multivariat digunakan untuk mengetahui variabel bebas yang paling mempengaruhi variabel terikat. Analisa multivariat menggunakan uji regresi binary logistic.

\section{HASIL DAN PEMBAHASAN \\ Analisis Univariat}

Berdasarkan tabel 1. dari 32 responden $(100 \%)$ diketahui umur responden mayoritas ibu berusia 20-35 tahun sebanyak 17 orang (53\%) dan ibu yang berusia $>35$ tahun sebanyak 15 orang $(47 \%)$. Berdasarkan pendidikan mayoritas ibu berpendidikan SMA sebanyak 19 orang $(59,4 \%)$, selanjutnya ibu yang berpendidikan perguruan tinggi (PT) sebanyak 7 orang $(21,9 \%)$, sedangkan ibu yang berpendidikan SMP sebanyak 6 orang $(18,7 \%)$. Dari pekerjaan responden mayoritas ibu tidak bekerja (IRT) sebanyak 19 orang $(59,4 \%)$, sedangkan ibu yang bekerja (wiraswasta, PNS) sebanyak 13 orang $(40,6 \%)$. Dari paritas ibu mayoritas ibu multipara sebanyak 24 orang $(65,6 \%)$, selanjutnya ibu yang primipara sebanyak 8 orang $(228,1 \%)$, sedangkan ibu yang grande multipara hanya 2 orang $(6,3 \%)$.

Berdasarkan hasil penelitian distribusi frekuensii variabel independen dan variabel dependen dapat dilihat pada tabel berikut ini.

Berdasarkan hasil penelitian bahwa diperoleh dari 32 responden, mayoritas ibu berpengetahuan kurang sebanyak 13 orang $(40,6 \%)$, sedangkan minoritas ibu yang berpengetahuan baik sebanyak 8 orang $(25 \%)$. Mayoritas ibu memiliki sikap positif sebanyak 20 orang $(62,5 \%)$, sedangkan minoritas ibu yang memiliki sikap negatif sebanyak 12 orang $(37,5 \%)$. Dari pekerjaan responden mayoritas yang tidak bekerja sebanyak 19 orang $(56,3 \%)$, dan minoritas 
responden yang bekerja sebanyak 13 orang $(40,6 \%)$.

Tabel 1.

Distribusi Frekuensi Responden Berdasarkan Umur, Pendidikan, Pekerjaan dan Paritas WUS di Puskesmas Sunggal Tahun 2020

\begin{tabular}{lcc}
\hline \multicolumn{1}{c}{$\begin{array}{c}\text { Karakteristik } \\
\text { Responden }\end{array}$} & $\begin{array}{c}\text { Jumlah } \\
(\mathbf{n})\end{array}$ & $\begin{array}{c}\text { Persentase } \\
(\%)\end{array}$ \\
\hline Umur & & \\
20-35 Tahun & 17 & 53 \\
>35 Tahun & 15 & 47 \\
Pendidikan & & \\
SMP & 6 & 18,7 \\
SMA & 19 & 59,4 \\
Perguruan Tinggi & 7 & 21,9 \\
Pekerjaan & & \\
Tidak Bekerja & 19 & 59,4 \\
Bekerja & 13 & 40,6 \\
Paritas & & \\
Primigravida & 9 & 28,1 \\
Multigravida & 21 & 65,6 \\
Grande Multigravida & 2 & 6,3 \\
\hline
\end{tabular}

Berdasarkan petugas kesehatan, mayoritas ibu yang mengatakan petugas kesehatan tidak berperan sebanyak 18 orang $(56,3 \%)$, sedangkan minoritas ibu yang mengatakan petugas kesehatan berperan sebanyak 14 orang (43,7\%). Berdasarkan kesediaan ibu mayoritas jumlah ibu yang bersedia melakukan pemeriksaan IVA sebanyak 17 orang $(53,1 \%)$, dan minoritas ibu yang tidak bersedia melakukan pemeriksaan IVA sebanyak 15 orang $(46,9 \%)$.

Tabel 2.

Distribusi Frekuensi Responden Berdasarkan Pengetahuan, Sikap, Dan Peran Petugas Kesehatan Dengan Kesediaan WUS dalam Pemeriksaan IVA di Puskesmas Sunggal Tahun 2020

\begin{tabular}{lcc}
\hline \multicolumn{1}{c}{ Variabel } & $\begin{array}{c}\text { Jumlah } \\
\text { (n) }\end{array}$ & $\begin{array}{c}\text { Persentase } \\
(\%)\end{array}$ \\
\hline Pengetahuan & & \\
Kurang & 13 & 40,5 \\
Cukup & 11 & 34,3 \\
Baik & 9 & 25,2 \\
Sikap & & \\
Negatif & 12 & 37,5 \\
Positif & 20 & 62,5 \\
Peran Petugas & & \\
Kesehatan & & \\
Tidak Berperan & 18 & 56,3 \\
Berperan & 14 & 43,7 \\
Pekerjaan & & \\
Tidak Bekerja & 19 & 56,3 \\
Bekerja & 13 & 40,6 \\
Kesediaan Ibu WUS & & \\
Tidak Bersedia & 15 & 46,9 \\
Bersedia & 17 & 53,1 \\
\hline
\end{tabular}

Analisis Bivariat

Hubungan variabel independen dan dependen dalam analisis bivariat dapat dilihat pada tabel berikut.

Tabel 3.

Tabulasi Silang Antara Pengetahuan, Sikap, Peran Petugas Kesehatan dan Pekerjaan dengan Kesediaan Ibu dalam Pemeriksaan IVA di Puskesmas Sunggal Tahun 2020

\begin{tabular}{|c|c|c|c|c|c|c|c|}
\hline \multirow{3}{*}{ Variabel Penelitian } & \multicolumn{4}{|c|}{ Pemeriksaan IVA } & \multirow{2}{*}{\multicolumn{2}{|c|}{ Jumlah }} & \multirow{3}{*}{ p Value } \\
\hline & \multicolumn{2}{|c|}{ Tidak Bersedia } & \multicolumn{2}{|c|}{ Bersedia } & & & \\
\hline & $F$ & $\%$ & $f$ & $\%$ & $\mathbf{F}$ & $\%$ & \\
\hline \multicolumn{8}{|l|}{ Pengetahuan } \\
\hline Kurang & 11 & 34,3 & 2 & 6,2 & 13 & 40,5 & \multirow{3}{*}{0,02} \\
\hline Cukup & 2 & 6,2 & 9 & 28,1 & 11 & 34,3 & \\
\hline Baik & 2 & 6,2 & 6 & 19 & 9 & 25,2 & \\
\hline \multicolumn{8}{|l|}{ Sikap } \\
\hline Negatif & 10 & 31,3 & 2 & 6,2 & 12 & 37,5 & \multirow[t]{3}{*}{0,005} \\
\hline Positif & 5 & 15,6 & 15 & 46,9 & 20 & 62,5 & \\
\hline \multicolumn{7}{|l|}{ Peran Petugas Kesehatan } & \\
\hline Tidak Berperan & 14 & 43,8 & 4 & 12,5 & 18 & 56,3 & 0,000 \\
\hline Berperan & 1 & 3,1 & 13 & 40,6 & 14 & 43,7 & \multirow{4}{*}{0,166} \\
\hline Pekerjaan & & & & & & & \\
\hline Tidak Bekerja & 11 & 34,4 & 8 & 25 & 19 & 56,3 & \\
\hline Bekerja & 4 & 12,5 & 9 & 28,1 & 13 & 40,6 & \\
\hline
\end{tabular}


Berdasarkan hasil penelitian menunjukkan bahwa pengetahuan wus berhubungan dengan kesediaan pemeriksaan iva dengan nilai $p$-value $=$ $0.02<0.05$. Dari 13 orang ibu yang berpengetahuan kurang mayoritas tidak bersedia melakukan pemeriksaan iva sebanyak 11 orang $(34,3 \%)$.

Dari hasil penelitian menunjukkan sikap wus berhubungan dengan kesediaan pemeriksaan iva dengan nilai $p$-value $=0,005<0,05$. Dari 20 orang ibu yang memiliki sikap positif, mayoritas responden bersedia melakukan pemeriksaan IVA yaitu sebanyak 15 orang $(46,9 \%)$.

Hasil penelitian menunjukkan bahwa peran petugas kesehatan berhubungan dengan kesediaan WUS melakukan pemeriksaaan IVA dengan nilai $p$ value $=0,000<0,05$. Dari 18 responden yang mengatakan petugas kesehatan tidak berperan, mayoritas ibu tidak bersedia melakukan pemeriksaan IVA yaitu sebanyak 14 orang $(43,8 \%)$
Hasil penelitian menunjukkan bahwa tidak ada hubungan pekerjaan dengan kesediaan WUS dengan nilai $p$-value $=0.166>0,05$. Dari 19 responden yang tidak bekerja, mayoritas ibu tidak bersedia melakukan pemeriksaan IVA yaitu sebanyak 11 orang $(34,4 \%)$.

\section{Analisis Multivariat}

Berdasarkan analisis bivariat pada penelitian ini menunjukkan bahwa variabel yang memenuhi syarat dijadikan model pada uji logistik ganda adalah peran petugas kesehatan $(p=0,035)$, selanjutnya dilihat bahwa faktor peran petugas kesehatan mempengaruhi kesediaan WUS dalam pemeriksaan IVA dengan nilai $\operatorname{Exp(B)~19,257~yang~}$ artinya petugas kesehatan yang berperan dalam memberikan penyuluhan kepada WUS mempunyai peluang 19,257 kali lebih besar ibu bersedia melakukan pemeriksaan IVA dibandingkan petugas kesehatan yang tidak berperan.

Tabel 4.

Hasil Uji Regresi Logistik Ganda Variabel Pengetahuan, Sikap, Peran Petugas Kesehatan dan Pekerjaan Yang Mempengaruhi Kesediaan WUS dalam Pemeriksaan IVA di Puskesmas Sunggal Tahun 2020

\begin{tabular}{lcccccccc}
\hline & \multirow{2}{*}{ B } & \multirow{2}{*}{ S.E. } & \multirow{2}{*}{ Wald } & \multirow{2}{*}{ df } & \multirow{2}{*}{ Sig. } & \multirow{2}{*}{ Exp(B) } & \multicolumn{2}{c}{ 95\% C.I.for EXP(B) } \\
\cline { 8 - 10 } & & & & & Lower & Upper \\
\hline Pengetahuan & 1,759 &, 777 & 1,222 & 1 &, 269 & 2,362 &, 515 & 10,833 \\
Sikap & 1,214 & 2,018 & 1 &, 155 & 5,611 &, 520 & 60,578 \\
Peran Petugas Kesehatan & 2,958 & 1,405 & 4,429 & 1 &, 035 & 19,257 & 1,225 & 302,610 \\
Pekerjaan & $-1,059$ & 1,363 &, 604 & 1 &, 437 &, 347 &, 024 & 5,012 \\
Constant & $-6,833$ & 2,453 & 7,758 & 1 &, 005 &, 001 & & \\
\hline
\end{tabular}

\section{PEMBAHASAN}

Hubungan Pengetahuan terhadap Kesediaan WUS dalam Pemeriksaan IVA di Puskesmas Sunggal Tahun 2020

Berdasarkan hasil uji statistik chi-square di dapatkan nilai $p$-value $=0,02$. Dengan demikian $p$ $=0.02<0.05$ artinya menunjukkan bahwa ada hubungan pengetahuan dengan kesediaan WUS dalam pemeriksaaan IVA di Puskesmas Sunggal Tahun 2020.

Hasil penelitian ini sejalan dengan penelitian yang dilakukan oleh Tini Yulaikha (2019) menunjukkan ada hubungan bermakna dan positif antara pengetahuan ibu dengan perilaku pemeriksaan IVA (Yulaikha 2019). Penelitian yang dilakukan oleh Ni Komang Puspita dewi, dkk (2018) juga menunjukkan bahwa ada hubungan bermakna antara pengetahuan WUS dengan keikutsertaan ibu dalam pemeriksaan Inspeksi Visual Asam Asetat (IVA) (Nurtini, Dewi, and Puspita Dewi 2018). Demikian penelitian yang dilakukan oleh Nur'aini dan Marinta Ulina (2020) bahwa variabel yang paling dominan berpengaruh terhadap tindakan pemeriksaan test IVA dalam deteksi dini kanker leher rahim adalah variabel pengetahuan ( $p$ value $=$ 0,000; OR = 1.700) (Nur'aini and Ulina 2020).

Menurut asumsi peneliti hasil penelitian ini menunjukkan bahwa ibu yang berpengetahuan kurang namun bersedia melakukan pemeriksaan ini menjelaskan bahwa kesediaan ibu dalam pemeriksaan IVA tidak hanya di pengaruhi oleh pengetahuan. Faktor lain yang mempengaruhi seperti dukungan teman atau orang terdekat. Adapun lbu yang berpengetahuan cukup namun tidak bersedia melakukan pemeriksaan. Hal ini menjelaskan pengetahuan yang cukup saja belum tentu membuat ibu bersedia melakukan pemeriksaan. Alasannya yaitu ibu memiliki jumlah anak yang banyak sehingga menjadi penghambat untuk melakukan pemeriksaan karena sibuk melakukan aktivitas di rumah dan tidak memiliki waktu banyak untuk melakukan pemeriksaan ke puskesmas. Sedangkan ibu yang berpengetahuan baik namun tidak bersedia melakukan pemeriksaan 
menjelaskan bahwa pengetahuan baik apabila tidak di dukung oleh sikap yang positif maka hasilnya tidak ada, ibu tidak memiliki kemauan dan kesadaran untuk melakukan pemeriksaan serta tidak ada dukungan dari suami untuk mengingatkan ibu untuk melakukan pemeriksaan.

\section{Hubungan Sikap terhadap Kesediaan WUS dalam Pemeriksaan IVA di Puskesmas Sunggal Tahun 2020}

Berdasarkan hasil uji statistik chi-square di dapatkan nialai $p$-value $=0.005$. Dengan demikian $p=0.005<0.05$ menunjukkan bahwa ada hubungan sikap dengan kesediaan WUS melakukan pemeriksaaan IVA di Puskesmas Sunggal Tahun 2020.

Dari hasil penelitian yang dilakukan oleh Suratin dan Susanti(2017) yaitu ada hubungan yang bermakna antara sikap ibu dengan pemeriksaan IVA di Puskesmas Sekupang (Suratin and Susanti 2017). Penelitian ini juga sejalan dengan penelitian yang dilakukan oleh Sartika Dewi Angriani, dkk (2019) bahwa sikap terdapat hubungan yang signifikan antara sikap dengan partisipasi perempuan usia beresiko dalam pemeriksaan IVA yaitu 0,040 atau <0,05 (Angriani, Natosba, and Girsang 2019). Berdasarkan penelitian yang dilakukan oleh Devy Lestari Maria, dkk (2018) terdapat hubungan yang bermakna antara sikap dengan keikutsertaan pekerja seks komersial dalam melakukan pemeriksaan IVA (Aulia and Neno 2019).

Menurut asumsi peneliti dari hasil penelitian yang menunjukkan bahwa masih dijumpai ibu memiliki sikap positif namun tidak bersedia melakukan pemeriksaan IVA. Hal Ini menjelaskan bahwa sikap yang positif belum tentu berperilaku positif. Alasannya karena malu untuk melakukan pemeriksaan dan juga takut dengan hasil yang di dapatkan setelah melakukan pemeriksaan IVA. Sedangkan ibu yang memiliki sikap negatif namun bersedia melakukan pemeriksaan menjelaskan bahwa ibu memiliki kesadaran yang tinggi akan kesehatan, sehingga ibu bersedia untuk melakukan pemeriksaan.

\section{Hubungan Peran Petugas Kesehatan terhadap Kesediaan WUS dalam Pemeriksaan IVA di Puskesmas Sunggal Tahun 2020}

Berdasarkan hasil uji statistik chi-square di dapatkan nilai $p$-value $=0,000$. Dengan demikian $p=0.000<0.05$ menunjukkan bahwa ada hubungan peran petugas kesehatan dengan kesediaan WUSmelakukan pemeriksaaan IVA di Puskesmas Sunggal Tahun 2020.
Penelitian ini sejalan dengan penelitian yang dilakukan oleh Sartika Dewi Anggriani, dkk (2019) bahwa ada hubungan bermakna antara peran petugas kesehatan dengan partisipasi perempuan beresiko dalam pemeriksaan IVA (Angriani et al. 2019). Penelitian yang dilakukan Paskalia Tri Kurniati (2019) menunjukkan bahwa ada hubungan yang bermakna antara peran petugas kesehatan dalam praktik pemeriksaan IVA pada perempuan usia fertile (Kurniati 2019).

Menurut asumsi peneliti hasil penelitian ini menunjukkan bahwa petugas kesehatan tidak berperan namun ibu bersedia melakukan pemeriksaan IVA. Ini menjelaskan bahwa informasi tidak hanya didapatkan dari petugas kesehatan. Banyak media yang dapat memberikan ibu informasi khususnya terkait pemeriksaan IVA seperti televisi, sosial media seperti facebook dan instagram. Sedangkan ibu yang mengatakan petugas kesehatan berperan namun tidak bersedia melakukan pemeriksaan IVA di karenakan ibu bekerja sehingga tidak punya waktu luang untuk melakukan pemeriksaan.

\section{Hubungan Pekerjaan terhadap Pemeriksaan IVA di Puskesmas Sunggal Tahun 2020}

Berdasarkan hasil uji statistik chi-square di dapatkan nilai $p$-value $=0.166$, dengan demikian $p=$ $0.166>0.05$ menunjukkan bahwa tidak ada hubungan pekerjaan dengan kesediaan WUS dalam melakukan pemeriksaaan IVA di Puskesmas Sunggal Tahun 2020.

Hasil penelitian ini sesuai dengan penelitian yang dilakukan oleh Mei Sondang, dkk (2018) bahwa tidak ada hubungan yang signifikan antara pekerjaan terhadap perilaku ibu (30-50) tahun dalam melakukan pemeriksaan IVA (Sondang and Hadi 2019). Berbeda dengan penelitian yang dilakukan oeh Elisabet Surbakti, dkk (2020) bahwa ada hubungan yang signifikan antara pekerjaan dengan deteksi dini kanker leher rahim (Sianturi, Surbakti, and Dorina Pasaribu 2015). Penelitian ini tidak sejalan dengan penelitian yang dilakukan oleh Sartika Dewi Angriani, dkk (2019) bahwa terdapat hubungan yang signifikan antara pekerjaan dengan partisipasi perempuan usia beresiko dalam pemeriksaan IVA yaitu 0,027 atau $<0,05$. Dalam penelitian ini menjelaskan bahwa seseorang yang bekerja akan memiliki pengetahuan yang luas dari seseorang yang tidak bekerja karena dengan bekerja seseorang akan mendapat informasi dan pengalaman (Angriani et al. 2019).

Menurut asumsi peneliti hasil penelitian ini menunjukkan bahwa mayoritas ibu tidak bekerja namun tidak bersedia melakukan pemeriksaan IVA. 
Ini menjelaskan bahwa meskipun ibu tidak bekerja, kesibukan ibu mengurus anak di rumah juga mempengaruhi pemeriksaan dan ibu tidak mendapat informasi tentang adanya pemeriksaan IVA di Puskesmas. Sedangkan ibu yang bekerja namun bersedia melakukan pemeriksaan, ini menjelaskan bahwa ibu sadar akan pentingnya menjaga kesehatan khususnya tentang deteksi dini kanker serviks dengan pemeriksaan IVA. Dengan keadaan sehat maka ibu akan bisa bekerja. Sedangkan apabila ibu sakit, maka ibu tidak akan bisa bekerja.

\section{Hubungan pengetahuan, sikap, peran petugas kesehatan dan pekerjaan terhadap kesediaan WUS dalam pemeriksaan IVA}

Berdasarkan asumsi peneliti, petugas kesehatan yang berperan akan membuat WUS 19,257 kali bersedia melakukan pemeriksaan IVA. Dengan demikian, perlu adanya penyuluhan dan pemberian informasi kepada ibu untuk meningkatkan pengetahuan dan kesadaran agar ibu bersedia untuk melakukan pemeriksaan. Menurut peneliti, semakin giat petugas kesehatan memberikan penyuluhan kepada ibu, maka akan semakin baik kesadaran ibu tentang pemeriksaan IVA. karena dengan adanya peran dari petugas kesehatan dalam pemberian informasi maka ibu-ibu akan tergerak hatinya bahwa melakukan pemeriksaan IVA sangat penting. Pemberian informasi tidak hanya pada ibu, tapi suami dan keluarga juga sangat perlu. Dengan adanya dukungan dari suami dan keluarga maka ibu akan semakin yakin untuk melakukan pemeriksaan.

\section{SIMPULAN}

Pengetahuan WUS berhubungan dengan kesediaan pemeriksaan IVA di Puskesmas Sunggal Tahun 2020 dengan nilai $p=0.02<0.05$.

Sikap WUS berhubungan dengan kesediaan pemeriksaan IVA di Puskesmas Sunggal Tahun 2020 dengan nilai $p=0,005<0,05$.

Peran petugas kesehatan berhubungan dengan kesediaan WUS melakukan pemeriksaaan IVA di Puskesmas Sunggal Tahun 2020 dengan nilai $p=0,000<0,05$.

Pekerjaan WUS tidak berhubungan dengan dengan kesediaan pemeriksaaan IVA di Puskesmas Sunggal Tahun 2020 nilai $p=0.166>0,05$.

Variabel yang paling berpengaruh dengan kesediaan WUS dalam pemeriksaan IVA di Puskesmas Sunggal Tahun 2020 adalah peran petugas kesehatan dengan nilai $p=0,035$, kemudian dilihat faktor peran petugas kesehatan mempengaruhi kesediaan WUS dalam pemeriksaan
IVA dengan nilai $\operatorname{Exp}(B) \quad 19,257$ artinya petugas kesehatan yang berperan dalam memberikan penyuluhan kepada WUS mempunyai peluang 19,257 kali lebih besar bersedia melakukan pemeriksaan IVA dibandingkan petugas kesehatan yang tidak berperan.

\section{SARAN}

Diharapkan hasil penelitian ini dapat menambah pengetahuan dan pengalaman WUS tentang pemeriksaan IVA dalam mendeteksi dini kanker leher rahim di Puskesmas Sunggal. Bagi tenaga kesehatan agar lebih intensif dan menjadwalkan memberikan penyuluhan pada ibuibu khususnya mengenai deteksi dini kanker serviks dan faktor resiko terjadinya kanker serviks, kemudian memasang poster dan memberikan leaflet pada pasien yang melakukan kunjungan. Bagi Puskesmas Sunggal agar lebih meningkatkan lagi promosi kesehatan khususnya terkait dengan pemeriksaan IVA.

\section{DAFTAR PUSTAKA}

Angriani, Sartika Dewi, Jum Natosba, and Bina Melvia Girsang. 2019. "Faktor Deerminan Partisipasi Perempuan Usia Berisiko Dalam Pemeriksaan Inspeksi Visual Asam Asetat (IVA)." JKM (Jurnal Kesehatan Masyarakat) Cendekia Utama. doi: 10.31596/jkm.v6i2.294.

Apriyanti, Nurhimah, Vida WiraUtami, Yuli Yantina, and Dessy Hermawan. 2020. "Faktor Faktor Yang Berhubungan Dengan Pemeriksaan $\mathrm{Ca}$ Servik Menggunakan Metode Visual Asam Asetat (IVA)." Jurnal Kebidanan Malahayati. doi: 10.33024/jkm.v6i1.1705.

Aulia, Devy Lestari Nurul, and Yulisa Neno. 2019. "Pengetahuan, Sikap Dan Motivasi Pekerja Seks Komersial Terhadap Keikutsertaan Pemeriksaan IVA." Jurnal Kebidanan Malahayati. doi: 10.33024/jkm.v5i4.2026.

Biro Komunikasi dan Pelayanan Masyarakat. 20116. "Pemeriksaan Dini Kanker Di Lingkungan Kemenkes Dalam Rangka HUT DWP Ke-17 Dan Hari Ibu Ke-88."

Dinas Kesehatan Provinsi Sumatera Utara. 2018. Profil Kesehatan Provinsi Sumatera Utara 2017.

Dinkes Provinsi Jawa Tengah. 2019. Buku Saku Kesehatan Triwulan 2 Tahun 2019.

Fallis, A. .. 2013. "Keikutsertaan Wanita Pasangan Usia Subur(pus) Dalam Melakukan." Journal of Chemical Information and Modeling 53(9):1689-99. doi: 
10.1017/CBO9781107415324.004.

Indonesia, Profil Kesehatan. 2018. Profil Kesehatan Indonesia 2017.

Kementrian Kesehatan RI. 2019. Hari Kanker Sedunia 2019.

Kesehatan, Profil, and Kota Medan. 2016. "Profil Kesehatan Kota Medan."

Kurniati, Paskalia Tri. 2019. "Dukungan Suami Dan Dukungan Petugas Kesehatan Terhadap Perilaku Pemeriksaan Iva Pada Wanita Usia Subur." doi: 10.33486/jrphs.v1i1.18.

Marmi. 2015. Kesehatan Reproduksi. Yogyakarta: Pustaka Belajar.

Nur'aini, and Marinta Ulina. 2020. "Pengaruh Faktor Internal Dan Eksternal Terhadap Tindakan Wanita Usia Subur Dalam Deteksi Dini Kanker Serviksmelalui Pemeriksaan Test IVA."

Nurtini, Ni Made, Komang Purnama Dewi, and $\mathrm{Ni}$ Wayan Erviana Puspita Dewi. 2018. "Karakteristik Wanita Usia Subur Yang Melakukan Inspeksi Visual Asam Asetat Di Kelurahan Renon." Jurnal Riset Kesehatan Nasional. doi: 10.37294/jrkn.v1i1.35.

Release, Press. 2018. "Press Release N 263." (September):13-15.

Sianturi, Efendi, Elisabet Surbakti, and Rina Dorina
Pasaribu. 2015. "Inspection Visual of Acetic Acid (IVA) Strategy for Early Detection of Cervical Cancer at the Community Health Centre Namorambe Deli Serdang District." International Journal of Science and Research. doi: 10.21275/22091703.

Soebandi. n.d. "Jurnal Kesehatan." 8(1):81-87. doi: 10.36858/jkds.v8i1.166.

Sondang, Mei, and Ella Nurlaella Hadi. 2019. "Dukungan Suami Terhadap Perilaku WUS (30-50 Tahun) Dalam Melakukan Pemeriksaan IVA Di Wilayah Kerja Puskesmas Bondongan Tahun 2018." Gaster. doi: 10.30787/gaster.v17i2.368.

Suratin, and Susanti. 2017. "Hubungan Pengetahuan Dan Sikap Ibu Terhadap Deteksi Dini Kanker Serviks Dengan Pemeriksaan IVA Di Puskesmas Sekupang Tahun 2017." Kedokteran 7(3):38-44.

Tilong, adi D. 2012. Bebas Dari Ancaman Kanker Serviks. edited by N. Sawitri. Jogjakarta: Flashbooks.

Yulaikha, Tini. 2019. "Hubungan Pendidikan, Pengetahuan Dan Sikap Ibu Tentang Kanker Serviks Dengan Perilaku Pemeriksaan IVA Di Puskesmas Godean II." 